Laboratorio de Arte,4-1991 http://dx.doi.org/10.12795/LA.1991.i04.12

\title{
APORTACIONES AL ESTUDIO DE LA CUSTODIA DE BAENA
}

\author{
por Francisco Cosano Moyano
}

\begin{abstract}
Se aportan noticias sobre la realización de la custodia procesional de Baena analizando la obra inicial de 1737, la ampliación posterior de 1782, y finalmente la restauración de 1945. Asimismo se dan a conocer las marcas de la obra, los patronos que la pagaron, y los artistas que la realizaron. Junto con los esquemas ideales y reales de la pieza se aporta la documentación correspondiente a ella.

New information is presented concerning the Baena processional custodial, analysing the initial work of 1737, the further additions of 1782 and, finally, the 1945 restoration. An account is also given of the hallmarks, the patrons who financed the work and the artists who carried it out. The corresponding documentation is provided, together with the original and the final sketches of the piece.
\end{abstract}

La fiesta del Corpus, tan arraigada en todo el orbe católico, data del año 1264 tras ser instituida por el papa Urbano IV. Con anterioridad el culto a la Eucaristía se celebraba desde los primeros años del cristianismo. Pero va a ser el papa Juan XXII quien abogue por la procesión pública de este sacramento, cuyo oficio ritual será compuesto en gran parte por Santo Tomás de Aquino. Es desde estos precisos momentos cuando podemos considerar el aspecto ceremonial y festivo del ritual, si bien sabemos por datos testimoniales que antes de esta fecha ya se festejaban procesiones en determinadas ciudades entre las que se encontraban Sevilla y Lieja.

También, y desde los primeros momentos de la reconquista cristiana, la ciudad de Baena celebraba esta festividad en cuya organización y sostenimiento participaban el Cabildo, los gremios y las propias hermandades titulares - Santa María la Mayor, San Pedro, San Bartolomé...-. Esta ceremonia evolucionará 
hacia una manifestación en la que el pueblo se va a convertir en espectador y protagonista de la misma; así vemos como contribuye en el exorno de las calles y crea bellas y efímeras arquitecturas al tiempo que participa en vistosas danzas, siendo por ello el verdadero artífice de la escenografía de la fiesta que, de este modo, se convierte en una mezcla de acontecimientos religiosos y profanos. Espectáculo y culto se unen para pasar a ser más un regocijo popular que un motivo de fe.

Ya Valverde Perales en su historia de Baena nos dice: "la fiesta del Corpus es de las que más antiguas noticias se tiene en la villa, celebrándose con gran solemnidad y alegría y, de entre las costeadas por el Ayuntamiento, la de mayor esplendor". Así el año 1664 los gastos fueron de 3.247 y un cuarto de reales que se invirtieron en pagar las danzas, la música -que incluía las del Corpus y la octava-, el adorno de las calles y los fuegos de artificio '.

Antiguamente los altares se erigían uno en el "Coso" y otro en las "Monjas", y la procesión regresaba a la iglesia entrando por la Puerta del Angel. A partir de 1884 la ceremonia se realizaba por la tarde según una bula del papa León XIII, y durante algún tiempo acompañaba al Santísimo una imagen de cada iglesia titular, costumbre que aún hoy perdura en algunas ciudades, pero que en Baena pronto decayó.

Las hermandades de cada parroquia se sustentaban de las aportaciones de los hermanos, de donaciones y censos, y de testamentos donde se dejaban legados como el de M. a de la Asunción y Luque -vecina de Baena-, que deja bienes raíces a la Hermandad de Santa María y normas concretas para la realización del pedestal de la custodia.

En el siglo XVIII se acentuarán las desigualdades entre las hermandades del Santísimo determinadas por las diferencias económicas existentes entre las parroquias. Santa María la Mayor se verá empobrecida al disminuir la población de la Almedina y ser su feligresía de escasos recursos económicos. Esta situación se agravará con el incendio sufrido en 1726 por la parroquia, hasta tal punto fue así que el Cabildo votó ayudar con una subvención de cien ducados a dicha hermandad en el año 1729. Posteriormente en 1781 perdería esta asignación por quiebra del Cabildo ${ }^{2}$. Es precisamente en este período, en el que la hermandad goza de esta asignación, cuando se manda realizar la custodia el año 1737.

La fiesta del Corpus en Baena mantuvo un gran esplendor durante los siglos XVI, XVII y XVIII, pero a partir del reinado de Carlos III, con la supresión de todo lo accesorio al espíritu de la celebración junto a los aires constitucionales del siglo posterior, se producirá el declive de la misma al convertirse en una

\footnotetext{
1. VALVERDE PERALES, F.: Historia de la Villa de Baena. Córdoba, 1908, pp. 274 y 275.

2. Vid. el artículo de JIMÉNEZ GORDILLO, titulado.: "El Corpus en la Villa de Baena: Aspectos económicos y sociales". Revista Cabildo. Baena, 1986, pp. 125 y ss.
} 
manifestación meramente religiosa, reducida sólo a lo procesional y en la que el pueblo es un simple espectador.

La Hermandad de Santa María, titular de la custodia, se revitalizará de hecho en los años de la postguerra española al conformarse de nuevo su junta cofradiera y sustentarla económicamente un grupo de hermanos.

Córdoba, mientras tanto, durante el siglo XVII y especialmente el XVIII será un centro de producción de orfebrería importante. La ciudad cuenta con obradores de renombre de los que saldrán importantes custodias cinceladas por las manos de artistas reconocidos, como es el caso del platero Bernabé García de los Reyes (autor al que se le atribuye la custodia de 1737) y Damián de Castro, su yerno, que adquirirá justa fama por su peculiar estilo personal.

El XVIII es el siglo de oro de la platería cordobesa. La centuria comienza con los plateros Juan de Torres y Juan Sánchez Izquierdo y durante la misma la producción de obras será abundante y se distribuirán por todo el territorio nacional y allende fronteras, sobre todo las piezas cinceladas en el taller de Damián de Castro, que darán origen a un elegante y movido estilo: "el rococó cordobés". Esta corriente creativa hará escuela a la que pertenecerá sin duda Antonio José de Santa Cruz y Zaldúa.

La gracia y fantasía de los modelos creados en esta época compiten con to mejor del rococó francés. Sin duda en ello debió influir Miguel Verdiguier, marsellés afincado en esos momentos en Córdoba y autor de obras como los púlpitos de la Catedral, la decoración barroca de la escalera del antiguo colegio del Obispado -hoy biblioteca provincial- o de los triunfos a San Rafael -Plaza del Potro y el situado junto a la Puerta del Puente en la Catedral-. Además también influirán en la orfebrería cordobesa los grabados de Bartolomé Vázquez que en estos momentos reside en la Corte.

Para Sentenach los dos grandes artistas cordobeses de este siglo fueron Cristóbal Sánchez Soto y Damián de Castro, dos admirables artistas del barroco a los que se deben las piezas de más bello aspecto. Sus obras poseen un repujado en grado inverosímil y cincelado y burilado admirable. De la filigrana cordobesa dice: "que se ejecutan piezas de gran belleza revestidas de una gracia, suntuosidad y primor especial" 3 .

\section{Fases en la realización de la Custodia}

El estado actual de la Custodia de Baena es el resultado de las sucesivas aportaciones que se le han ido incorporando como consecuencia de la evolución del gusto artístico o simplemente determinadas por modas que en un momento

\footnotetext{
3. SENTENACH, N.: Bosquejo histórico sobre la Orfebrería Española. Madrid, 1909, pp. 128 y ss.
} 
dado se generalizan. Así, desde la primitiva custodia del año 1737 hasta su actual configuración, ésta ha sufrido variaciones en su aspecto estructural e iconográfico. Variaciones propiciadas por adiciones a la obra de fábrica y complementadas con nuevos motivos ornamentales implantados en el año 1782 o bien debidas a la restauración llevada a cabo en 1945 . Etapas de todo un proceso que analizamos a continuación:

\section{La primitiva Custodia de 1737}

Se realizó en este año como constaba en la antigua inscripción que se hallaba al pie del pedestal y donde también se podía leer que fue costeada por los hermanos de la Cofradía del Santísimo de Santa María la Mayor ${ }^{4}$.

Está atribuída al platero cordobés Bernabé García de los Reyes -atribución a la que nos sumamos- ya que carece de punzones, los cuales presumiblemente desaparecieron al incorporarle en su base el pedestal rococó ${ }^{5}$.

A esta fase inicial de la primitiva custodia corresponden los tres cuerpos: el primero, cerrado y con función de alto zócalo, reserva su interior para un pequeño sagrario. El segundo, cuerpo principal por excelencia y de mayores proporciones, es diáfano en sus cuatro frentes y queda reservado para ubicación del ostensorio, que en una primera etapa -antes de ser reemplazado por el de Santa Cruzcorrespondería al del siglo XVII, puesto que existe una íntima relación dimensional, ornamental e iconográfica. El tercero, cuerpo de menores proporciones y de una más sobria ornamentación, sirve de templete a la advocación de la iglesia titular de la custodia. Sobre la cornisa del cuerpo principal y a cada ángulo, flanqueando el cuerpo superior, los cuatro doctores de la Iglesia en actitud vigilante: San Agustín, San Jerónimo, San Ambrosio y San Gregorio ${ }^{6}$.

4. La inscripción dice así: "La hermandad del Santísimo de esta villa de Baena, y devoción de ciento ocho fieles, costearon tres cuerpos de esta Custodia, año de 1737, y D. María de la Asunción Porras (.), vecina de ella, por su testamento dejó su caudal para un pedestal a dicha Custodia, el que por D. Cristóbal de Gamboa, presbítero, mayordomo del Santísimo, y D. Joaquín de Cabra, rector de la iglesia de San Pedro, sus fideicomisarios, se hizo con el último cuerpo aumento de los otros tres, y custodia para manifestar; todo con peso de 2.650 onzas de plata, cuya obra se ejecutó por D. Antonio J.P.H. Santa Cruz en Córdoba año de 1782".

(.) Posible error en la transcripción ya que su apellido es Luque según podemos comprobar en su testamento. Quizás se confunda con el de D. $\stackrel{a}{ }$ Bernarda Porras, tía suya, que le deja en herencia unas casas. Tampoco se refiere a los apellidos de su esposo que eran Arrabal Repiso.

5. Nos sumamos a la atribución que de la autoria de la obra se hace en el Catálogo histórico artistico de la provincia de Córdoba, en la persona del platero Bernabé García de los Reyes. Ya que si comparamos la estilística formal, tanto en el tratamiento del cincelado ornamental como en relieves y esculturas de la misma, con otras obras punzonadas por el autor - Custodia de la catedral de Teruel, Custodia de Espejo, urna eucarística de Santa M. ${ }^{\mathrm{a}}$ del Soterraño de Aguilar de la Frontera- nos llevan a esta adjudicación.

6. Para una mayor profundización en la tipología e iconografía de la Custodia consúltese el estudio monográfico del mismo autor titulado: La Custodia de Asiento de Santa María la Mayor de Baena, en estos momentos en fase de publicación por Adisur.

Vid. también SANZ SERRANO, M.. JESÚS.: Juan de Arfe y Villafañe y la Custodia de Sevilla, en Arte Hispalense. Sevilla, 1987. 
Ya al exterior, y coronando todo el conjunto, una bonita imagen de la Fe dotada de un gracioso movimiento muy del gusto manierista.

\section{La ampliación del 1782}

Es tendencia generalizada en el período barroco la adición de zócalos con la finalidad de engrandecer y resaltar todo lo religioso. Medio siglo más tarde se le incorpora a la primitiva fábrica de la custodia el pedestal rococó. Su autor, Antonio de Santa Cruz y Zaldúa, eleva el tabernáculo sobre una forma acampanada de movidas superficies laterales, integrando su obra -no de una manera acertada según mi opinión- a la unidad del conjunto. Además incorpora elementos ornamentales en cornisas y esquineras y remata todo el conjunto con una cimera de volutas donde apoya la figura de la Fe.

Obra más acertada, salida de sus manos, es el magnífico ostensorio que más adelante analizamos.

\section{La restauración de 1945}

Por estos años se organiza de nuevo la Hermandad de Santa María y se acuerda por su junta, como consta en el acta correspondiente, su restauración. Se le encarga al platero cordobés Felipe Castillo Suárez, siendo el coste de la restauración 25.000 pesetas, que se distribuyeron de la siguiente manera: por la mano de obra 17.000, por las cuatro figuras de las virtudes 6.000 y por los dos ángeles del pedestal 2.000 pesetas. Además se le entregan al platero $83 \mathrm{Kg}$. en restos de plata, de los cuales $61 \mathrm{Kg}$ y 300 gramos correspondían a trozos deteriorados de la custodia ${ }^{7}$. Aunque en el libro de Actas no se menciona explícitamente, tenemos que hacer constar que en estos momentos también se debió realizar la actual figura de la $\mathrm{Fe}$, quedando incorporada a la fábrica de la custodia en sustitución de la primitiva imagen desaparecida - comparaciones fotográficas de la obra, de antes y después de la restauración de 1945, nos llevan a ello-.

La disposición iconográfica del pedestal sufre variaciones a consecuencia del deterioro producido por la profanación de la obra en los inicios de nuestra contienda civil. En la restauración se sustituyen los atributos pasionales destruidos y pasan a ocupar su lugar los relieves que se encontraban en el interior del cuerpo que realiza la función de sagrario.

Por último, bajo la cimera de volutas que remata la custodia, se coloca un nuevo pelícano y se le añaden más campanillas.

7. Hermandad del Santísimo de Santa María la Mayor de Baena. Acta correspondiente al 10 de abril de 1945. 
El pedestal y el ostensorio de 1782

El pedestal de la Custodia de Baena, de planta cuadrada y salientes diagonales en sus esquinas que dibujan elegantes volutas -base de los cuatros ángeles que recostados sostienen atributos pasionales y de los cuatro pináculos, típicos y diferenciadores de las custodias cordobesas-, recibe una tipología acampanada a manera de tronco de pirámide, con superficies movidas por donde discurren motivos de tipo geométrico que enlazados se distribuyen determinando espirales. Presidiendo cada frontal aparecen cartelas con relieves entre volutas y rocallas.

Las cuatro pirámides, de sección triangular, están bellamente cinceladas en sus tres caras cuyas concavidades se revisten ornamentalmente de temática pasional y eucarística. De los tres ángulos de sus bases arrancan elegantes cardinas de tipo romano que le sirven de apoyo y asiento. En ritmo ascendente sus paredes quedan adornadas con triple juego de guirnaldas de rosas en plata sobredora$\mathrm{da}$, que disminuyen de tamaño según se acercan a la cúspide piramidal. $\mathrm{Su}$ remate sirve de apoyo a la personificación de las virtudes que portando sus propios símbolos rodean al expositor a la misma altura.

La iconografía del pedestal ha sufrido con el tiempo transformaciones. Ya Valverde Perales nos la describe así: "En las volutas asientan cuatro ángeles que sostienen atributos de la Pasión, tras ellos se alzan cuatro pirámides que rematan con las virtudes Prudencia, Justicia, Fortaleza y Templanza. Al frente se ve la Santa Cena repujada y debajo el Sagrado Corazón de Jesús, al costado derecho el Cordero y bajo Él atributos de la Pasión; al izquierdo los exploradores y otros atributos de la Pasión; al respaldo el pelícano con un león debajo" ${ }^{8}$. Su autor dispuso la iconografía del pedestal al unísono de su magnífico ostensorio, éste mucho más acertado en cuanto al tratamiento formal y estilístico al no tener que integrarlo de una manera fija al conjunto de la obra.

Los relieves que hoy aparecen en el pedestal datan de la restauración llevada a cabo el año 1945, ya que se trasladaron los del interior del sagrario -la Asunción, el Buen Pastor y los Panes de la Proposición- de la primitiva custodia a las cartelas del pedestal de Santa Cruz, pero con una leve modificación: el Sagrado Corazón pasa a ocupar el paño posterior en beneficio de la Asunción que preside el frontal. En el paño derecho se coloca el Buen Pastor y en el izquierdo los Panes de la Proposición.

En los obeliscos piramidales, vestigios de las antiguas torres esquineras, observamos iconografías pasionales, símbolos eucarísticos y atributos martiriológicos ornamentando sus caras. De esta manera podemos apreciar cincelados de hojas de vid, sarmientos, racimos de uva, cálices, haces de espigas, gallos, estan-

8. VALVERDE PERALES, F.: Op. cit., pp. 307 y 308. 
dartes, columnas y látigos, lanzas, escaleras, alabardas, hisopos..., que se repiten mezclados y resueltos con un cincelado plano adaptado en tamaño a la superficie lateral de los pináculos, que a manera de pedestal sirven de base a las cuatro virtudes: Fortaleza y Justicia al frente y Prudencia y Templanza al fondo.

Nos resulta evidente a simple vista el contraste entre el barroco inicial, mezclado con elementos del bajo renacimiento y el manierismo propio de la primitiva custodia, y el pedestal de 1782 concebido en el más riguroso rococó que rinde pleitesía a la orfebrería cordobesa del siglo XVIII, cuando ya en su segunda mitad están surgiendo renovadores aires neoclásicos. Aunque, según palabras del profesor Ortiz Juárez, "el medio siglo que dista entre una y otra obra no acentúa la diferencia que pueda perjudicar a la grandiosidad del conjunto" 9 .

Es curioso advertir como Damián de Castro al realizar el pedestal para la Custodia de Cabra integra el mismo al conjunto cediendo complicaciones formales y ornamentales en aras de una mayor unidad. Aquí ya vislumbramos la evolución y el cambio producido en la obra del importante platero cordobés que con mayor claridad apreciamos en la Custodia de La Rambla, donde aparecen ya motivos del renovador estilo neoclásico. Al mismo tiempo se continúa haciendo el más exigible rococó hasta finales de siglo, prueba palpable de la fijación del mismo en el gusto popular que hace imponer sus preferencias al artista que le encarga la obra -posiblemente el caso de Baena con Santa Cruz-.

El ostensorio de mano, revestido de una gran riqueza y preciosismo artístico, es obra más acertada que el pedestal aunque de un módulo mayor si lo referimos al espacio en el que va ubicado procesionalmente. Con un movido pie de planta cuadrada, de tipología bulbosa y acampanada, es del más exquisito gusto rococó. Su base apoya en cuatro esquinas sobre ménsulas que sostienen ángeles que portan atributos de la Pasión y en los laterales cartelas enmarcadas con ricos moldurajes de rocallas que recogen relieves pasionales: al frente el Santo Rostro; la columna, el látigo y la corona de espinas en el lateral izquierdo; la cruz, lanza y esponja en el lateral derecho, y ya en la parte posterior el León de Judá. La ubicación y disposición iconográfica que el autor sigue en el ostensorio es la misma que la primitiva del pedestal -lógico por otra parte al haber salido del mismo taller-, que tenía estos mismos símbolos además del Corazón de Jesús.

El nudo del ostensorio queda flanqueado por dos grandes ángeles que en actitud abierta erigen entre sus manos el viril. Esta disposición la encontramos en otras obras como el ostensorio en forma de arca de la

9. ORTIZ JUÁREZ, D.: Catálogo de la Exposición de Orfebrería Cordobesa. Córdoba, 1973, p. 88. 
mitad del XVIII de la catedral cordobesa, el "Monumento" que se levanta el Jueves Santo en la catedral sevillana y en la urna de San Fernando, las dos últimas de Laureano de Pina.

El viril, de los de sol, queda rodeado por un nimbo de cabezas de querubines que se enlazan entre sí con espigas y hojas de vid. Recientemente se le han añadido y engarzado joyas y pedrería al ostensorio que, como bien dice el profesor Ortiz Juárez, enmascaran la belleza de esta custodia portátil.

Tanto el ostensorio como el pedestal aparecen punzonados con el fiel contraste de Mateo Martínez Moreno, el de autor de Antonio José de Santa Cruz, y el león de la ciudad de Córdoba. 
Huellas obtenidas de los punzones en el ostensorio
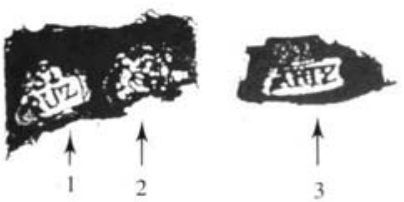

1. Punzón de autor

2. Punzón de la ciudad de Córdoba

3. Punzón del fiel contraste

Fotografia de las marcas de los punzones en el pedestal

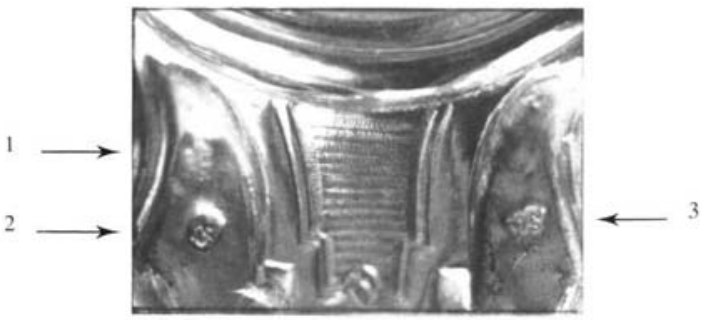

1. Punzón del fiel contraste

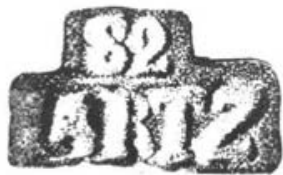

2. Punzón de la ciudad de Córdoba

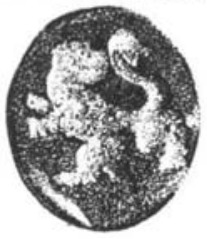

3. Punzón de autor

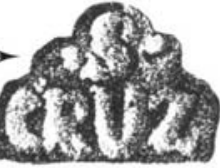


El autor del pedestal y el ostensorio: Antonio José de Santa Cruz y Zaldúa

Nace en Córdoba el ocho de septiembre de 1733 y es bautizado doce días más tarde por el rector Don Francisco Blanco Mellado de Cea en la parroquia de San Nicolás y Eulogio del barrio de la Ajerquía donde residen sus padres, Juan Francisco de Santa Cruz y Luque y Alejandra María Teresa de Zaldúa y Villarreal, los dos naturales de Córdoba.

En el año 1748 solicita ante el Ilustre Colegio de la Venerable Congregación de San Eloy de esta ciudad se le hagan las pruebas y concedan licencia para entrar a aprender en cualquier obrador de artífice aprobado. En estos momentos es hermano mayor de la Cofradía Don Bernardo de Heredia y Estrada y secretario Don José Gabriel Ceballos y Bonrostro.

El seis de junio del mismo año obtiene la licencia según mandan las reales ordenanzas. Su acta de aprobación dice así: "Aprobaron y mandaron dar licencia al dicho pretendiente con toda la autoridad necesaria que a nos toca para que pueda cualquier artífice aprobado de los de nuestro Colegio recibirlo por su discípulo y aprenda el arte de platería y así mismo se le haga su asiento en el libro de discípulos que tiene y guarda esta Congregación (libro de recibimiento de Discípulos número 89, p. 17), y mandar poner estos autos de información en el archivo de nuestro Colegio con los demás que en él se guardan así lo acordaron y firmaron dichos señores, del que yo el secretario de este Colegio y Congregación doy fe. Firmado: Bernardo de Heredia y Estrada, Francisco Galindo y Morales. Juan Sánchez Izquierdo. José Gabriel Ceballos y Bonrostro, secretario" 10.

Santa Cruz entra de aprendiz en el taller-obrador de Juan Lovero o Lorero -según Ortiz Juárez, Dorero o Dardero-. Cinco años más tarde, el once de abril de 1753 presenta certificación de Don Juan Lorero ante el Ilustre Colegio y pide que se le honre ser admitido a examen exhibiendo para ello un esquilón de plata salido de sus manos, que fue complacencia de los examinadores y que tras varias preguntas al autor le aprobaron y dieron licencia para abrir obrador y tener trato y comercio en los géneros de platería tanto en esta ciudad como en los demás reinos y señoríos de España ".

Santa Cruz instala su taller en la antigua calle Correo de Córdoba y de su obrador debieron salir numerosas piezas a tenor del número de trabajadores del mismo, ya que sabemos que en el año 1784 trabajaban seis oficiales y dos

\footnotetext{
10. (A)rchivo (H)istórico (M)unicipal de (C)órdoba. Papeles de la "(C)ofradía de (S)an (E)loy". Legajo n. ${ }^{2}$ 31. Pruebas de 1740 al 1749, documento n. ${ }^{2} 47$.

11. A.H.M.C.: Papeles de la C.S.E. Legajo n. ${ }^{2} 19$, documento n. ${ }^{2} 13$.
} 
aprendices, uno con pruebas y otro hijo de artífice ${ }^{12}$. Si este dato lo comparamos con el obrador, sito en la calle Pedregosa, del platero Damián de Castro -el de más fama del momento- que lo componían sólo cinco oficiales, podemos deducir el papel e importancia que desempeñó nuestro autor en la platería cordobesa del dieciocho y fundamentalmente en las décadas de los setenta y ochenta.

También su hijo, Antonio Rafael de Santa Cruz y Pedrajas, tenía abierto en los ochenta un obrador de importancia en la cuesta de San Benito donde trabajaban cinco oficiales y un aprendiz con pruebas. De este taller sale la plata cincelada que cubrirá la cruz procesional realizada en ébano de la hermandad de Nuestro Padre Jesús Nazareno de Fernán Núñez ${ }^{13}$. No debemos confundir sus obras con las de su padre, ya que las suyas aparecen punzonadas con la leyenda: SA, seguida de una cruz patada.

Nuestro autor fue nombrado segundo veedor de plata el veinticuatro de junio de 1767 y, siendo Damián de Castro el año 1779 hermano Mayor de la Congregación de San Eloy, primer veedor de plata ${ }^{14}$. Como observamos, Santa Cruz tuvo una relación estrecha con Castro, tanto personal como profesionalmente, siguiendo estilísticamente en sus obras la corriente creativa del maestro.

No son muchas las noticias que tenemos de Antonio José de Santa Cruz, sin duda alguna artista importante en la platería cordobesa debido a las numerosas obras que debieron salir de su taller y que hoy no están suficientemente catalogadas ni estudiadas por los especialistas. Este platero, que muere el dieciséis de mayo de 1793, merece un estudio más profundo.

Por último, entre sus obras más importantes, destacamos un atril del monasterio del Císter de Córdoba; un candelero de Nuestra Señora de la Asunción de Bujalance; un viso de sagrario de Santa Marta en Córdoba; un astil de cruz de Nuestra Señora del Carmen de Castro del Río; un cáliz en la iglesia de los Descalzos y otro en la de Santa María de Ronda; una cruz de altar en la iglesia de San Sebastián de Antequera ${ }^{15}$, y ya en Baena, un viso de sagrario y cañones de ciriales de Santa María la Mayor, así como el pedestal y el magnífico ostensorio de la custodia.

12. A.H.M.C.: Papeles de la C.S.E. Legajo $n .{ }^{2} 25$, documento $n .{ }^{2} 227$. Varios asuntos (Nombres de artífices que componen este ante de la platería y calle de su habitación).

13. Vid. el artículo de COSANO MOYANO, F.: "La Orfebrería Religiosa", en Revista de Feria. Fernán Núñez, 1987.

14. A.H.M.C.: Papeles de la C.S.E. Legajo n. ${ }^{2}$ 7. Libro I de Cabildos (sesiones celebradas el 22 de junio de 1770 $y$ el 24 de junio de 1779).

15. Estas tres piezas las cataloga TEMBOURY ALVAREZ, Juan, en su libro La Orfebrería Religiosa en Málaga. Málaga, 1948, pp. 272-295 y 311. 
Diferentes punzones utilizados por Santa Cruz en sus obras, junto a otros de la ciudad de Córdoba ${ }^{16}$

Año

Autor

Ciudad

1778

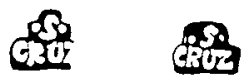

3 (3)

1779

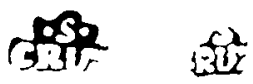

36

1783
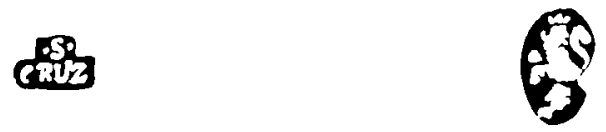

1787
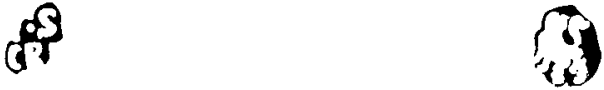

La donación del pedestal

Fue costeada por la hermana de la Cofradía del Santísimo Sacramento de Santa María la Mayor; María de la Asunción y Luque, que ya dejó expresada su voluntad testamentaria en el documento del año 1773 otorgado ante el escribano de Baena Joaquín José Mansilla. El escrito recoge en su interior todos los pormenores y condiciones de venta de sus bienes por sus nombrados albaceas, que lo han de hacer en almoneda pública y otorgarlos al mejor postor, siendo su importe

16. Vid. el apartado "Repertorio de marcas españolas", en Enciclopedia de la plata española y virreynal americana. en las páginas 127 y 128 se recogen las que aquí publicamos.

Vid. también ORTIZ JUÁREZ, D.: Punzones de platería cordobesa. Córdoba, 1980, pp. 135 y 136. 
depositado en una sola persona. Dice textualmente: "y junto todo lo conviertan en hacer un pedestal para la custodia que sale el día del Corpus el que siga la fábrica que tiene dicha custodia según le tengo comunicado y si para dicha fábrica no hubiese bastante quiero se venda el todo o parte como por bien tengan mis albaceas de la haza de diez y ocho fanegas útiles del sitio de la Gamonoza o Carrizales debida al Santísimo disponiendo en esta parte lo que por bien tengan o quitándola del todo, pues mi voluntad es salga en un todo perfecta y concluida la obra del pedestal de dicha custodia" ${ }^{17}$.

En el año 1780 , sintiéndose la donante próxima a morir, expresa una vez más su última voluntad ante el mismo escribano el día siete de marzo. Nuevamente deja confirmada su intención de donar a la Hermandad del Santísimo con estas palabras: "Mando a la cofradía del Santísimo Sacramento de dicha iglesia parroquial de Santa María la Mayor la haza de veinte y seis fanegas de tierra con el yesar que tiene la que se halla en el sitio de la Gamonosa o Carrizales", y tras precisar la situación de la finca prosigue "con la carga y pensión que perpetuamente y para siempre jamás han de celebrar en dicha iglesia una fiesta solemne con el Santísimo Sacramento, patente desde la hora tercia, y ha de asistir la música de esta villa y ha de haber sermón y se han de poner en el altar y manifiesto a lo menos setenta y dos luces cuya fiesta se ha de celebrar el día de la Asunción de Nuestra Señora". Deja dicho que no se litigue bajo ningún aspecto que contraríe su voluntad y para ello si fuera necesario dispongan, para no faltar a sus disposiciones, de otra haza sus albaceas. Si a pesar de ello surgiesen problemas nombra como fideicomisarios al hermano mayor de la hermandad del Santísimo y al rector de la iglesia de Santa María.

Más adelante expresa que llegado el momento de su muerte, sus albaceas se hagan cargo de sus bienes -especificando detalles ya expresados en su primer testamento- y con las ventas realizadas e intereses obtenidos manda: "se haga un pedestal de plata sobredorada para la custodia que sale el día del Corpus el que siga la fábrica que tiene dicha custodia, o mejor según les tengo comunicado" 18 -determina que sea sobredorada en su última voluntad-. Sólo se sobredoran algunos elementos ornamentales y en parte los relieves y esculturas. A sus albaceas les da amplios poderes frente a la justicia eclesiástica y secular.

Prosigue la donante contribuyendo con sus bienes a la iglesia y determinando las rentas que se han de utilizar como gastos en las festividades religiosas de la Inmaculada y la Asunción. Como es lógico, los testamentos de las personas adineradas y católicas reflejan la sociedad profundamente religiosa del momento y el poder que ejercía la Iglesia.

17. (A)rchivo (H)istórico (P)rovincial de (C)órdoba. Protocolo de Joaquín José Mansilla. Legajo 422-P, p. 67. Baena, año 1773.

18. A.H.P.C. Protocolo de Joaquín José Mansilla, Legajo 424-P, pp. 11 y 12. Baena, año 1780. 
Sus albaceas, Cristóbal de Gamboa, presbítero, y Joaquín de Cabra, rector de la iglesia de San Pedro, ante el escribano otorgan escritura de venta a favor de Juan Trujillo, natural de la villa de Baena, que resultó ser el mejor pujador de la haza de dos fanegas de tierra calma en la peña Omar en el sitio de la media legua y cuya subasta salía en la cantidad de mil ochocientos sesenta reales, quedando adjudicada al citado en dos mil trescientos reales. Habiéndose seguido en todo momento la voluntad de D. a María de la Asunción, sus albaceas otorgaron escritura, previo deseo del pujador, de esta manera: "declaramos es propia dicha haza de esta testamentaria en cuya forma la vendemos con sus entradas y usos, costumbres y derechos y servidumbres cuantos tiene y les pertenece por libre de toda carga, que declaramos no la tiene, y así esta testamentaría lo asegura y la vendemos en precio de los ya referidos dos mil trescientos reales, que para el fin de hacer el pedestal que sirva en la custodia que sale el día del Corpus, y para ponerlo en seguro depósito como fue la voluntad de la testadora ahora recibimos de presente en moneda de plata / peso / duro / de a veinte reales a vista del presente escribano y testigos a quien le pedimos de fe de ello" ${ }^{19}$. La escritura se firmó el dieciséis del mes de junio de 1780 por el escribano Joaquín José Mansilla y los testigos, vecinos de la villa, D. Francisco Valenzuela Rueda, Julián Piernagorda y Francisco de Murcia.

19. A.H.P.C. Protocolo de Joaquín José Mansilla. Legajo 424-P, p. 48. Baena, año 1780. 


\section{APÉNDICE DOCUMENTTLL}

\section{DOCUMENTO N. ${ }^{2} 1$}

Testamento otorgado por D." María de la Asunción y Luque ante el Escribano Joaquín José Mansilla en el año 1780, (el de la muerte de la testante) donde deja expresada su donación a la Hermandad del Santísimo Sacramento de la Parroquia de Santa María la Mayor de Baena.

Dada la complejidad y amplitud del Documento, hemos considerado oportuno el transcribir y reproducir aquí solamente aquellas partes que atañen directamente a la pieza de orfebrería de la que tratamos.

... Disponiendo mis Albazeas que con el todo de estos Yntereses sehaga un Pedes / tral de plata sobre Dorada para la Custodia que sale el Dia del / Corpus el que siga la fabrica que, tiene dcha Custodia, o mexor se / gun les tengo comunicado, Y saben mi Yntencion qual es, Dando / les adhos mis Albazeas las facultades mas amplias que serequieren / y si sobre este asunto uotro qualquiera quisieren tomarles cuentas / nieguense aello pues tengo entera satisfacion delos susodchos y pro / hibo alos Señores Jueces y Justicias Ecleciasticas ô seculares el que / con ningun pretexto se puedan Yntroducir en mis bienes nime / nos con mis Albazeas porque no tienen obligazion a Llebar / cuentaformal denada ni seles hade prescisar aello por que / quiero Se este por lo que los Dos Dispongan segun aqui llebo expuesto $Y$ les / tengo Comunicado...

7-Marzo-1780.

\section{DOCUMENTO N.으 2}

Documento otorgado por los Albaceas de D. a. María de la Asunción y Luque, ante el Escribano Joaquín José Mansilla, el 18 de Junio de 1780, donde queda reflejada la venta de bienes que se hizo, tal y como la testante lo tenía dispuesto en su testamento, para que el producto de esta venta sirviera para sufragar los gastos del Pedestal que para la Custodia del Santísimo tenía encargado.

Por la misma razón que hemos referido en el Documento n.ำ 1, sólo transcribimos lo que atañe directamente a la obra que estudiamos.

$Y$ asi esta Testamentaria lo asegura y la ven / demos en precio de lo ya referido Dos mill y trescientos reales, que para el fin de ha / zer el pedestral que sirba en la Custodia que sale el Dia del Corpus, y para te / nerlo en seguro deposito, como fue la voluntad de la testadora, aora recebimos / de presente en Moneda de plata Duros de abeinte reales a bista del pre / sente Escribano y testigos a quienes pedimos den Fee de ello = E yo Joxchin Josef Mansilla Esc / publico de Numo de esta Villa de Baena Doy fee Y Testimonio que a mi presencia delos Testigos que se expresaran, El dcho Juan Truxillo Entregó a los nominados Don Cristobal / Gamboa y Don Joachin de Cabra, Albazeas Testamentarios y Fideicomisarios de la D. ${ }^{a}$ Ma / ria de la Asunción los referidos Dos mill y tresciento reales los que quedaron en su poder / realmente $Y$ con Efecto $=$.

I8-Junio-1780. 


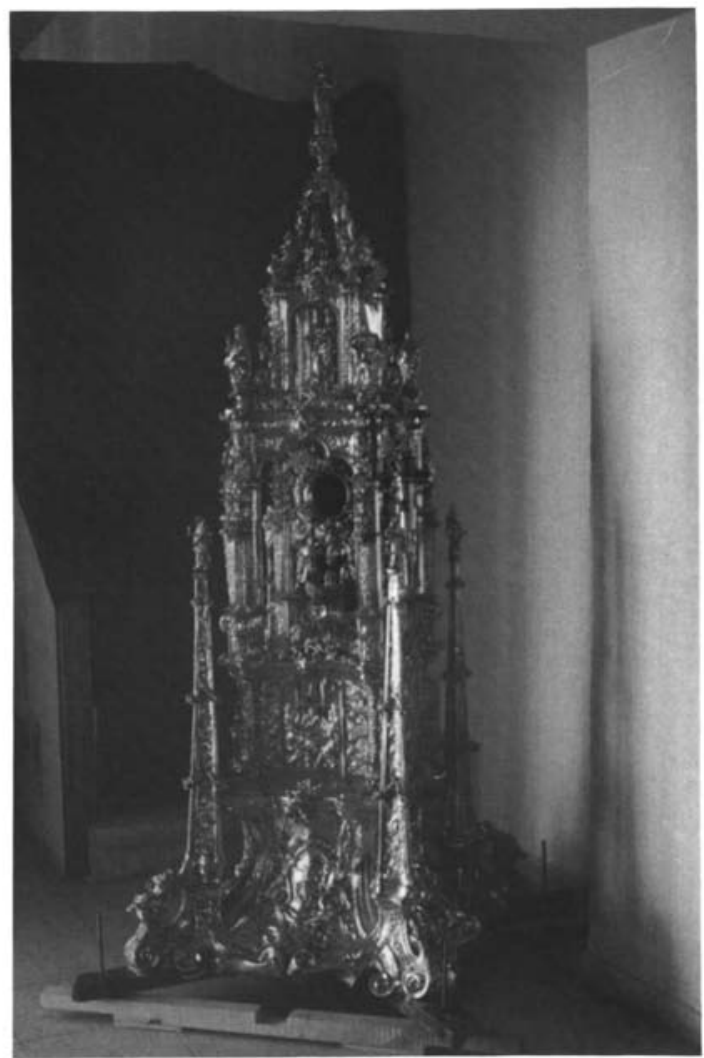

Custodia de Bacna. Siglo XVIII (1737-1782), García de los Reyes - Santa Cruz y Zaldúa. Plata en su color y sobredorada. Altura $2,34 \mathrm{~m}$. 


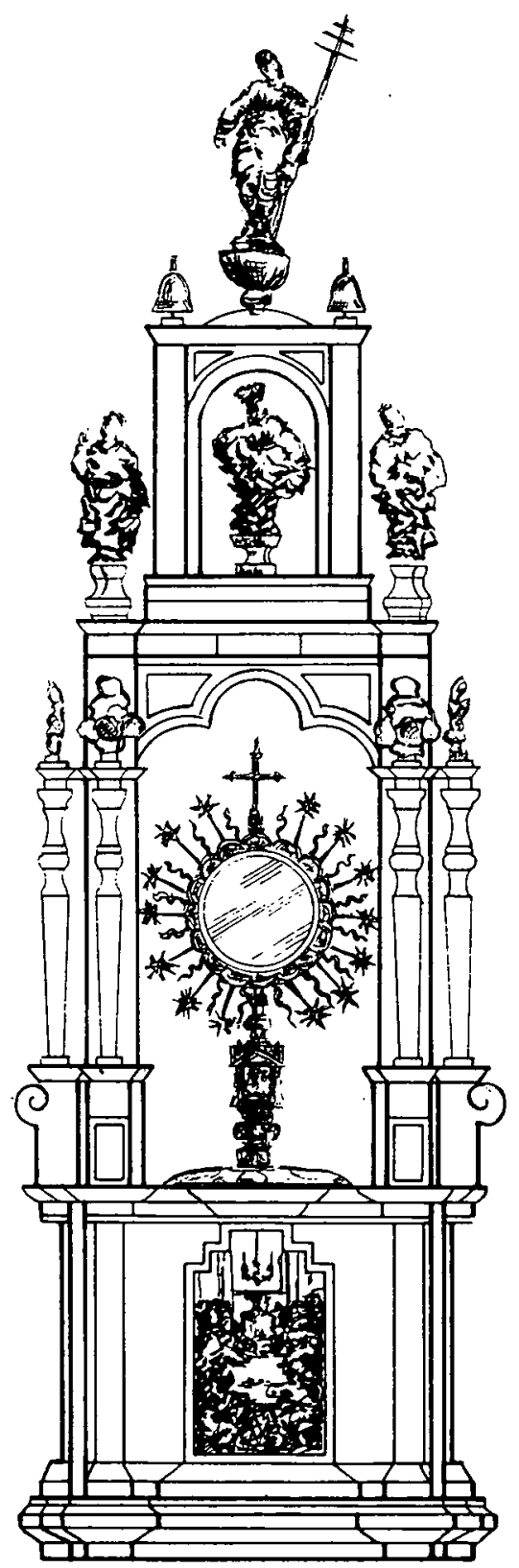

Dibujo ideal de la Custodia de 1737 con el Ostensorio de la segunda mitad del siglo XVII. Atribuida a Bemabé García de los Reyes. 


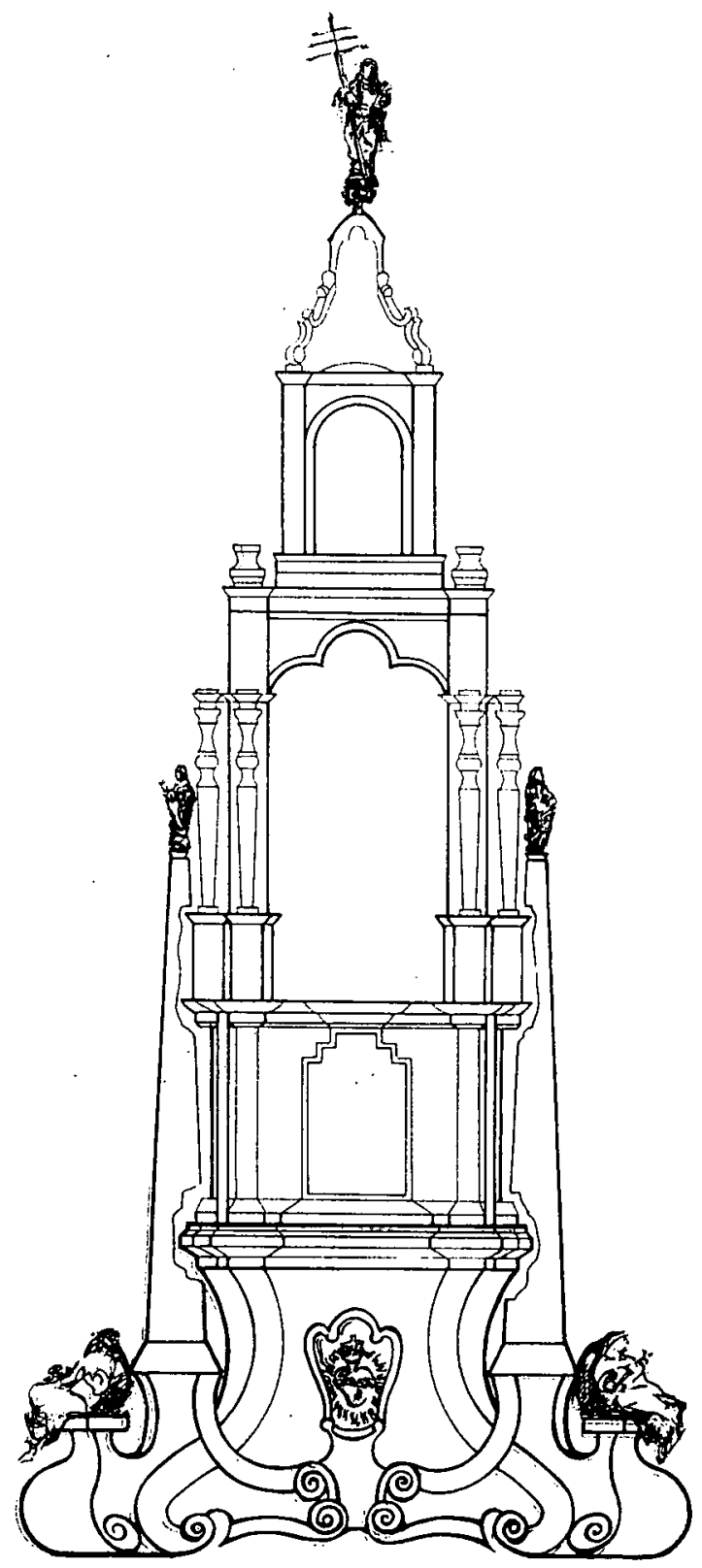

Dibujo aproximado de la Custodia en 1782, después de la incorporación del pedestal y la cimera de volutas por Antonio José de Santa Cruz y Zaldúa. La imagen de la Fe corresponde al año 1945. Medida en altura 2,34 m. 


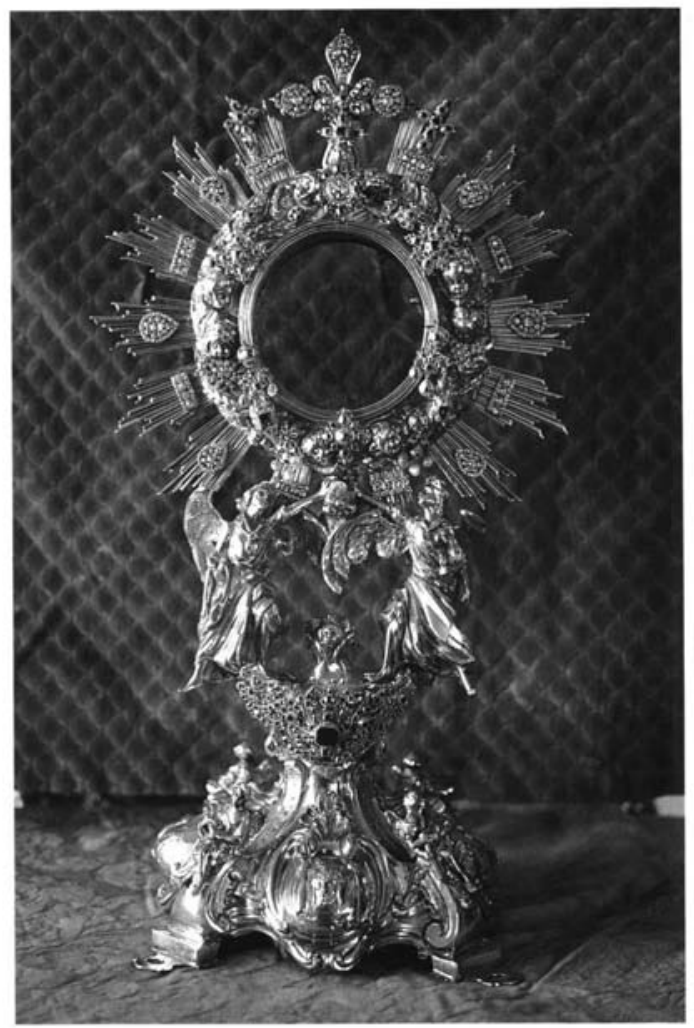

Ostensorio, Siglo XVIII -1782-. Plata en su color y sobredorada. Antonio José de Santa Cruz y Zaldúa. Altura $56 \mathrm{~cm}$. 